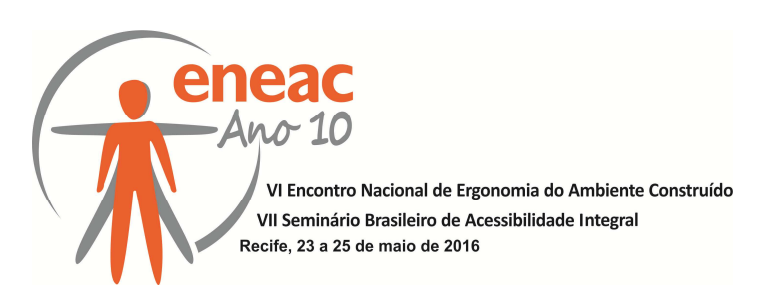

\title{
PROPOSTAS DE ADAPTAÇÕES DE ACESSIBILIDADE BASEADAS NA NBR 9050: ESTUDO DE CASO NO HOSPITAL UNIVERSITÁRIO WALTER CANTÍDIO
}

\author{
PARAHYBA, Thaís Gontijo Araújo (1); \\ ELIAS, Sergio José Barbosa (2); \\ ZURBA, Nadia Khaled (3) \\ (1) Universidade Federal do Ceará, Eng. Graduada \\ e-mail:thaisgontijo@hotmail.com \\ (2) Universidade Federal do Ceará, Doutor \\ e-mail:serglias@secrel.com.br \\ (3) Universidade Federal do Ceará, Doutora

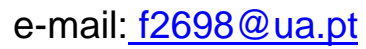

\begin{abstract}
RESUMO
Acessibilidade é um tema bastante discutido nas últimas décadas por profissionais e técnicos na área de projetos, bem como no âmbito acadêmico devido a sua essencial funcionalidade nos ambientes. Neste trabalho foi analisado, através de documentação direta, vivência prática, visitas técnicas e um questionário, pontos de melhorias em um subsistema do Hospital Universitário Walter Cantídio. Após esta análise, a pesquisa concluiu que se necessitam de significativas alterações ergonômicas no Setor de Marcação de Consultas, para que possa assegurar no local o acesso, a inclusão e o conforto de portadores de deficiências e/ou mobilidade reduzidas, conforme as exigências da norma NBR 9050/2015.
\end{abstract}

Palavras chave: Ergonomia; deficiência; acessibilidade e NBR 9050.

\begin{abstract}
O Accessibility is a topic that has been widely discussed in recent decades by professionals and technicians in the project area as well as in the academic environment due to its essential functionality in environments, In this work, it was analyzed, through direct documentation, practical experience, technical visits and a questionnaire, some areas for improvement in a subsystem University Hospital Walter Cantídio. After this analysis, the research concluded that requires significant ergonomic changes in this subsystem, the Medical Appointment Scheduling Site, so you can ensure access, inclusion and comfort for people with disabilities and/or reduced mobility, as required by NBR 9050/2015.
\end{abstract}

Keywords: Ergonomics; deficiency; accessibility; NBR 9050. 


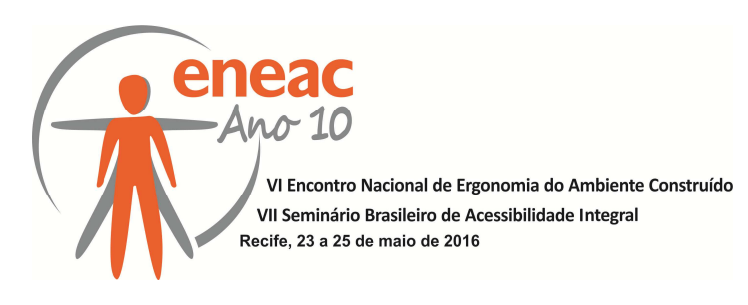

\section{INTRODUÇÃO}

Atualmente, os estabelecimentos públicos são concebidos em maior quantidade dentro do contexto urbano. O número de empreendimentos comerciais, edificações/conjuntos residenciais, creches, escolas, universidades, hospitais, entre outros, aumentam a cada ano em grande proporção.

Poucos desses estabelecimentos são construídos considerando as necessidades das pessoas que apresentem qualquer tipo de condicionamento físico especial, mesmo existindo normas e leis que visam normatizar a acessibilidade de pessoas com deficiência em edificações públicas, espaços, mobiliário e equipamentos urbanos e obrigam a concepção de projetos mais adequados e acessíveis, sendo uma delas a norma NBR 9050/2015 elaborada pela Associação Brasileira de Normas Técnicas (ABNT).

Apesar do tema acessibilidade já vir sendo bastante difundido, ainda se nota uma resistência de muitas organizações em se adequar às normas, o que, muitas vezes, pode ser considerado motivo de descaso para alguns, para outros é visto como custo elevado para a realização das reformas de adequação necessárias.

Este trabalho apresenta um estudo de caso em subsistema do Hospital Universitário Walter Cantídio (HUWC), localizado em Fortaleza - CE, onde o mesmo foi analisado, utilizando como parâmetro a NBR 9050/2015, e proposto algumas intervenções de melhorias a fim de possibilitar uma autonomia e usabilidade do equipamento/ambiente às pessoas que apresentem necessidades especiais relativas a uma deficiência física e/ou mobilidade reduzida.

\section{METODOLOGIA}

A fundamentação ergonômica para o desenvolvimento deste trabalho está compreendida pela aplicação da "Metodologia experimental de ensino-aprendizagem para o design de produtos biomédicos (BIO-MEAD)" (ZURBA et al., 2014). O respectivo conteúdo metodológico consiste em congregar um "conjunto de ações práticas, multidisciplinares e de assimilação de componentes teóricos que visam o estudo, análise e projeto de design de produtos para uso biomédico" (ZURBA et al., 2014), tendo por base a experimentação em ambiente hospitalar.

Foi feito um estudo de caso onde a referida metodologia propôs como documentação direta uma vivência prática sobre acessibilidade de pessoas com deficiências e mobilidade reduzida. Posteriormente, propôs a visita técnica ao HUWC que permitiu mapear processos e procedimentos adotados no ambiente em estudo, levando em consideração as inúmeras variáveis que os influenciam. O registro de informações foi realizado através de fotografias e desenhos documentais dos mobiliários e dos ambientes hospitalares, ou a falta deles.

Assim, foi possível desenvolver uma visão sistêmica dos setores do hospital e entrevistar os profissionais que vivenciam situações cotidianas, de modo a coletar informações substanciais para a definição de um problema mais específico (ARAÚJO, 2016).

\section{REVISÃO BIBLIOGRÁFICA}




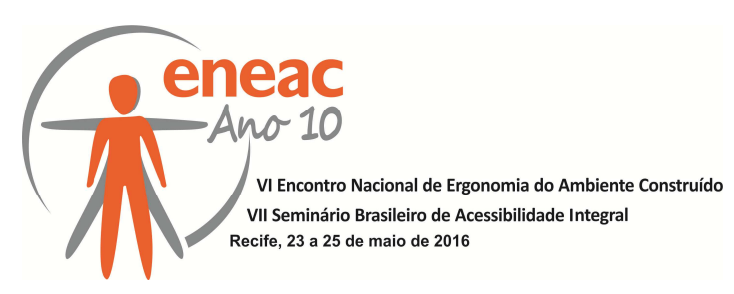

\subsection{Deficiência e Mobilidade Reduzida}

É comum a confusão entre os conceitos de deficiência e de incapacidade. São conceitos diferentes embora possam se relacionar. A presença de uma deficiência pode vir a implicar ou não em alguma incapacidade. É possível que um indivíduo portador de uma deficiência seja perfeitamente capaz de realizar tarefas e funções exercidas por pessoas com o estado biomédico normal e, por outro lado, um indivíduo que não apresente nenhum tipo de deficiência seja incapaz, em algum momento, de realizar alguma atividade, torna-se errônea a caracterização de incapacidade na primeira situação, levando em consideração que surgiram, ao longo dos anos, diversas tecnologias que auxiliam na realização de tarefas cotidianas, sem que a deficiência deixe de existir na pessoa.

Dischinger, Ely e Piardi (2012, p. 103), conceituam deficiência como uma "perda, anomalia ou disfunção no nível fisiológico do indivíduo, podendo ocorrer nos sistemas sensoriais, no sistema cognitivo e na estrutura físico-orgânica".

Em contrapartida, para determinar a incapacidade de uma pessoa é preciso que se avaliem, individualmente, as especificidades dessa condição, bem como o grau de comprometimento do indivíduo para realização das atividades normalmente realizadas por pessoas sem deficiência.

Apresenta-se como outro equívoco, o entendimento de que seria correta a relação entre deficiência e mobilidade reduzida, uma vez que problemas de flexibilidade, de coordenação motora e de assimilação através da inteligência, muitas vezes, se impõem por períodos determinados, ou seja, ocorrem por um tempo e depois são superados.

Pela Lei Brasileira de Inclusão da Pessoa com Deficiência de no 13.146/15 (BRASIL, 2015), pessoas com mobilidade reduzida são "aquelas que tenham, por qualquer motivo, dificuldade de movimentação, permanente ou temporária, gerando redução efetiva da mobilidade, da flexibilidade, da coordenação motora ou da percepção, incluindo idoso, gestante, lactante, pessoa com criança de colo e obeso".

\subsection{Acessibilidade}

O tema acessibilidade tem sido bastante discutido por profissionais de diversas áreas, pesquisadores e no âmbito acadêmico, a fim de determinar, através de leis, normas técnicas, padronizações e aplicação de conceitos de desenho universal, uma inclusão social mais efetiva e garantir a acessibilidade plena a serviços básicos como saúde e educação, bem como a edificações, mobiliários e elementos urbanos, de forma autônoma e segura para todos os indivíduos de nossa sociedade.

A NBR 9050/2015 (ABNT, 2015, p. 02), defini um ambiente acessível possui "espaços, mobiliários, equipamentos urbanos, edificações, transportes, informação e comunicação, inclusive seus sistemas e tecnologias ou elemento que possa ser alcançado, acionado, utilizado e vivenciado por qualquer pessoa".

Mesmo com leis, decretos, convenções e normas técnicas, ainda é alarmante a quantidade de indivíduos que enfrentam, em seu cotidiano, vários tipos de dificuldades de acesso na realização de atividades desejadas, sejam por obstáculos, sejam por barreiras, seja na comunicação, dentre outras. Ressaltam Dischinger, Ely e Piardi (2012) que ainda existem também problemas de acessibilidade que ainda não foram previstos nas leis e nas normas técnicas já existentes, destacando a fundamental importância do constante estudo e a atualização da legislação. 


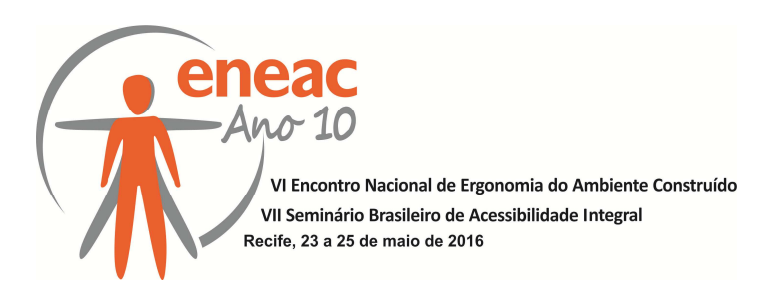

\subsection{NBR 9050}

Em 1994, a Associação Brasileira de Normas Técnicas (ABNT) criou a primeira norma técnica relativa à acessibilidade denominada na época de NBR 9050 - Acessibilidade de pessoas portadoras de deficiências a edificações, espaço mobiliário e equipamentos Urbanos.

Constam três edições da mesma: a primeira em 1994; a segunda em 2004, com alteração do título para "NBR 9050 - Acessibilidade a edificações, mobiliário, espaços e equipamentos urbanos", além de outras modificações; e a última, que foi recentemente revisada e passou a vigorar em outubro de 2015, manteve o mesmo título da edição anterior, mas atualizou parte do seu conteúdo.

A NBR 9050/2015 apresentou uma reorganização dos capítulos, passando-os de 09 (nove) para 10 (dez), dispostos ao longo de 162 páginas. A norma revisada englobou desde referências normativas, termos, definições, abreviaturas e parâmetros antropométricos, até critérios de informação e sinalização em espaços públicos, acessos e circulação em ambientes internos e externos, parâmetros de ergonomia para sanitários, banheiros e vestiários, intervenções em mobiliários e equipamentos urbanos, dentre outros pontos.

\section{ESTUDO DE CASO}

\subsection{Vivência Prática}

Com intuito de entender as dificuldades cotidianas das pessoas com necessidades especiais, foram utilizados artefatos que pudessem simular as sensações, da forma mais real possível. Encontrou-se os seguintes resultados:

- Deficiência visual: Primeiramente, ao tampar os olhos, simulando uma deficiência visual total, constou-se um aguçamento da audição e do tato. Torna-se de fundamental importância ouvir com bastante atenção o que o ambiente transmite e ter uma memória sensitiva para gravar modelos, espessuras, formas, texturas de objetos encontrados ao redor. Bengalas, de vários tipos, podem auxiliar durante os movimentos, contudo, pode-se sentir a necessidade de alguém acompanhando durante o caminho.

- Deficiência auditiva: Ao utilizar um protetor auricular e um fone de ouvido abafador, foi possível identificar grandes dificuldades ao andar nas ruas. Por não ter auxilio dos sons, a atenção precisou ser redobrada ao atravessar as ruas, andar em calçadas obstruídas de materiais, vendedores ambulantes, lixo, dentre outras.

- Deficiência de mobilidade: Para a simulação, foi utilizada uma cadeira de rodas. Nas ruas, há ainda uma ocupação indevida das calçadas por vendedores ambulantes, lixos, carros, dentre outros, que dificultam a passagem, além da falta de nivelamento e revestimento adequado dos pisos, falta de rampas e presença de buracos.

- Mobilidade reduzida: A simulação foi feita através dos artifícios muletas, onde foi possível vivenciar as dificuldades de uma pessoa que quebrou o pé, ou seja, uma situação provisória, e foram identificadas dificuldades similares às descritas anteriormente na simulação de deficiência de mobilidade utilizando a cadeira de rodas. 


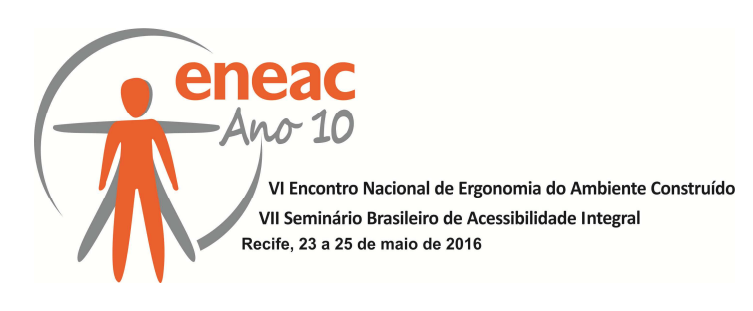

\subsection{Visita Técnica}

Após a Vivência Prática, realizou-se no dia 07 de abril de 2015 a Visita Técnica ao HUWC, proposta pela metodologia aplicada no trabalho em questão, a fim de documentar através de fotos, as situações do cotidiano, condições de equipamentos, acessibilidade e os ambientes hospitalares propriamente ditos. A visita foi acompanhada pelas arquitetas do hospital.

Através de entrevistas com administradores, foi ressaltado um problema no Setor de Marcação de Consultas (SMC). Ao visitar o setor, foi possível entender os motivos das reclamações, tanto dos funcionários como dos próprios pacientes. Unindo a necessidade do hospital e a de melhorar acessibilidade do setor, problemas repetidos em outros setores, o subsistema escolhido para se aplicar ou recomendar intervenções ergométricas e de acessibilidade foi o Setor de Marcação de Consultas (SMC).

\subsubsection{Setor de Marcação de Consultas}

Realizou-se uma análise ergonômica do subsistema selecionado, o SMC, a fim de identificar possíveis pontos de melhoria na acessibilidade do local.

De acordo com o relato dos funcionários, o SMC atende, em média, cerca de 500 pacientes por dia, sendo essa demanda bem sazonal durante o dia e durante o mês, ou seja, horários com picos e dias com mais de 500 pacientes, bem como horários tranquilos e dias com menos pacientes, embora sempre havendo filas. Durante uma manhã de acompanhamento, foi possível identificar uma grande quantidade de pacientes que, após enfrentar em pé a fila, não puderam marcar suas consultas devido à indisponibilidade do médico, falta de algum documento exigido ou por estar no local errado.

No SMC as consultas são marcadas através de filas, havendo a fila de prioridades, mas sendo a mesma em pé, sem ordenação por senhas. A fila de prioridades, além de atender idosos, gestantes, portadores de deficiências e/ou mobilidade reduzida, atende também os funcionários e estudantes do HUWC.

A acessibilidade na parte interna fica muito aquém do esperado, pois não há espaço para transitar e muito menos manobrar com a cadeira de rodas devido ao grande número de pessoas em pé nas filas, não há espaço de espera para cadeirantes e acompanhantes, não há assentos para pessoas obesas, dentre outras observações.

Os guichês são altos e o vidro quase todo preenchido com poucas aberturas, o que dificulta a comunicação entre pacientes e funcionários, já que para realizar o agendamento de consultas são necessárias trocas de informações como: a data e o horário de preferência, telefone de contato, dentre outras dúvidas.

Dentro dos guichês de atendimento encontrou-se pouco espaço para circulação, a porta de entrada não passa uma cadeira de rodas, devido à altura do guichê nota-se dificuldade de comunicação, pois o funcionário em atendimento precisa elevar a voz para que o paciente, do outro lado do vidro, possa entender as informações, dentre outros pontos.

\subsubsection{Questionário}

O questionário (Tabela 1) foi elaborado e aplicado pela autora, baseados nas planilhas propostas no Programa de Acessibilidade às Pessoas com Deficiência ou Mobilidade Reduzida nas Edificações de Uso Público de Dischinger, Ely e Piardi (2012). 


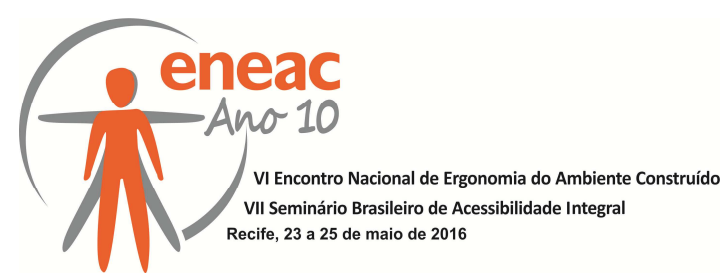

O objetivo do questionário foi analisar, através de itens pré-selecionados pela autora, as conformidades e não conformidades em relação à norma NBR 9050/2015. Considerando para tanto os itens da norma que mais se adequavam ao subsistema em estudo, baseandose nas observações feitas de possíveis pontos de melhoria e de quesitos que aparentaram ser de fundamental importância quanto à acessibilidade do SMC.

Como resposta para cada item avaliado, utilizou-se de 02 (dois) parâmetros básicos:

1 - Conforme ou adequado;

2 - Não conforme, inexistente ou não encontrado.

Ressalta-se a importância dos conhecimentos adquiridos durante a Vivência Prática e a Visita Técnica bem como no estudo da NBR 9050/2015 durante a elaboração do questionário, o que fundamentou como base teórica e prática, possibilitando identificar os itens da norma no subsistema, entender a real necessidade dos mesmos e o possibilitar o preenchimento mais correto possível da tabela

Tabela 1 - Questionário de acessibilidade

\begin{tabular}{|c|c|c|c|c|}
\hline \multicolumn{5}{|c|}{ QUESTIONÁRIO DE ACESSIBILIDADE } \\
\hline $\begin{array}{l}\text { ITEM } \\
\text { NBR } \\
9050\end{array}$ & QUESTIONÁRIO & Sim & Não & Observações \\
\hline 6.1.1.2 & $\begin{array}{l}\text { Há pelo menos uma rota acessível até a entrada do edifício } \\
\text { público, com um trajeto contínuo, desobstruído e sinalizado? }\end{array}$ & & & $\begin{array}{l}\text { Não podemos concluir que há uma rota } \\
\text { acessível. }\end{array}$ \\
\hline 6.3 .2 & $\begin{array}{l}\text { O piso do passeio possui material de revestimento e } \\
\text { acabamento regular, firme e estável em qualquer condição } \\
\text { climática? }\end{array}$ & & & $\begin{array}{l}\text { Sim, possui um piso regular, firme e } \\
\text { estável em qualquer condição climática. }\end{array}$ \\
\hline 5.4.6.4 & $\begin{array}{l}\text { Na ausência ou descontinuidade de linha-guia identificável, } \\
\text { há alguma sinalização tátil e visual direcional que auxilie o } \\
\text { direcionamento e deslocamento, indicando caminhos } \\
\text { preferenciais de circulação no ambiente interno e externo? }\end{array}$ & & & $\begin{array}{l}\text { Não há nenhuma linha guia e nem } \\
\text { sinalização tátil. }\end{array}$ \\
\hline 6.6.3 & $\begin{array}{l}\text { Havendo alguma escada, com três ou mais degraus no } \\
\text { acesso à entrada principal, a mesma possui largura mínima } \\
\text { de } 1,20 \mathrm{~m} ?\end{array}$ & & & $\begin{array}{l}\text { Sim, possui 3,60 de largura com } 5 \\
\text { andares. }\end{array}$ \\
\hline 6.3 .2 & $\begin{array}{l}\text { O piso da escada possui material de revestimento e } \\
\text { acabamento regular, firme e estável em qualquer condição } \\
\text { climática? }\end{array}$ & & & $\begin{array}{l}\text { Sim, possui um piso regular, firme e } \\
\text { estável em qualquer condição climática. }\end{array}$ \\
\hline 6.9.2.1 & $\begin{array}{l}\text { Os corrimãos estão instalados em ambos os lados da } \\
\text { escada? }\end{array}$ & & & $\begin{array}{l}\text { Não há corrimão em ambos os lados, } \\
\text { somente um intermediário. }\end{array}$ \\
\hline 6.9.2.1 & $\begin{array}{l}\text { Os corrimãos das escadas estão instalados na altura de } \\
0,92 \mathrm{~cm} \text { e a } 0,70 \mathrm{~cm} \text { do piso? }\end{array}$ & & & $\begin{array}{l}\text { Não, somente o intermediário atende às } \\
\text { medidas. }\end{array}$ \\
\hline 6.9.2.2 & $\begin{array}{l}\text { Os corrimãos laterais das escadas são contínuos e } \\
\text { possuem prolongamento mínimo de } 30 \mathrm{~cm} \text { nas } \\
\text { extremidades, sem interferir com áreas de circulação? }\end{array}$ & & & $\begin{array}{l}\text { O corrimão encerra junto com a rampa, } \\
\text { ou seja, não há o prolongamento } \\
\text { exigido na norma. }\end{array}$ \\
\hline 6.9 .4 & $\begin{array}{l}\text { Se tratando de uma escada com mais de } 2,40 m \text { de largura, } \\
\text { há um corrimão intermediário? }\end{array}$ & & & $\begin{array}{l}\text { Sim, conforme a norma, possui um } \\
\text { corrimão intermediário. }\end{array}$ \\
\hline 6.7 & $\begin{array}{l}\text { Há alguma rampa ou equipamento eletromecânico de } \\
\text { transporte vertical associado às escadas? }\end{array}$ & & & Sim, há uma rampa, conforme a norma. \\
\hline 6.3 .2 & $\begin{array}{l}\text { O piso da rampa possui material de revestimento e } \\
\text { acabamento regular, firme e estável em qualquer condição } \\
\text { climática? }\end{array}$ & & & $\begin{array}{l}\text { Sim, possui um piso regular, firme e } \\
\text { estável em qualquer condição climática. }\end{array}$ \\
\hline 6.6.2.5 & A largura mínima da rampa é de $1,20 \mathrm{~m} ?$ & & & $\begin{array}{l}\text { Conforme a norma, com 1,35m de } \\
\text { largura. }\end{array}$ \\
\hline 6.9.2.1 & $\begin{array}{l}\text { Os corrimãos da rampa estão instalados em ambos os lados } \\
\text { na altura de } 0,92 \mathrm{~cm} \text { e a } 0,70 \mathrm{~cm} \text { do piso? }\end{array}$ & & & Conforme a norma. \\
\hline 6.9.2.2 & $\begin{array}{l}\text { Os corrimãos laterais da rampa são contínuos e possuem } \\
\text { prolongamento mínimo de } 30 \mathrm{~cm} \text { nas extremidades, sem } \\
\text { interferir com áreas de circulação? }\end{array}$ & & & $\begin{array}{l}\text { O corrimão encerra junto com a rampa, } \\
\text { ou seja, não há o prolongamento } \\
\text { exigido na norma. }\end{array}$ \\
\hline 5.4.6.3 & $\begin{array}{l}\text { Na existência de desníveis, escadas, rampas, obras, postes, } \\
\text { telefones públicos, dentre outros, há sinalização tátil e visual } \\
\text { de alerta sobre eles? }\end{array}$ & & & $\begin{array}{l}\text { Não há nenhuma sinalização tátil e } \\
\text { visual de alerta. }\end{array}$ \\
\hline
\end{tabular}




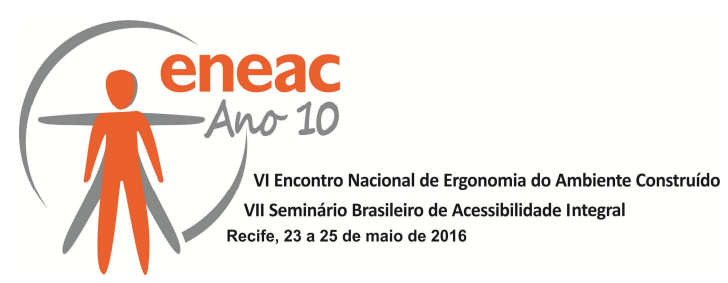

\begin{tabular}{|c|c|c|}
\hline 6.3 .2 & $\begin{array}{l}\text { O piso da área externa à porta de entrada possui material } \\
\text { de revestimento e acabamento regular, firme e estável em } \\
\text { qualquer condição climática? }\end{array}$ & $\begin{array}{l}\text { O piso foi considerado conforme a } \\
\text { norma. }\end{array}$ \\
\hline 5.3.2.2 & $\begin{array}{l}\text { Na entrada do edifício público acessível está fixado em local } \\
\text { visível o símbolo internacional de acesso? }\end{array}$ & Não há nenhuma sinalização visível. \\
\hline 6.11 .2 .4 & $\begin{array}{l}\text { A porta de entrada, quando aberta, possui um vão livre de } \\
\text { no mínimo } 80 \mathrm{~cm} \text { de largura e } 2,10 \mathrm{~m} \text { de altura? }\end{array}$ & $\begin{array}{l}\text { A porta de entrada é composta por } \\
\text { duas portas de vidro, com vão de } \\
\text { largura de } 2,25 \mathrm{~m} \text { e } 2,10 \mathrm{~m} \text { de altura. }\end{array}$ \\
\hline 6.2 .5 & $\begin{array}{l}\text { Há pelo menos uma opção que garanta acesso, manobra e } \\
\text { circulação de portadores de deficiência e/ou mobilidade } \\
\text { reduzida? }\end{array}$ & $\begin{array}{l}\text { Sim, há um dispositivo de catracas e } \\
\text { uma porta lateral que dá acesso ao } \\
\text { ambulatório, sanitários. }\end{array}$ \\
\hline 6.11 .1 & $\begin{array}{l}\text { Há corredores com larguras de no mínimo 1,50m quando se } \\
\text { tratando de uso público, com faixa livre de barreiras ou } \\
\text { obstáculos? }\end{array}$ & Conforme a norma. \\
\hline 6.3 .2 & $\begin{array}{l}\text { O piso dos corredores possui material de revestimento e } \\
\text { acabamento regular, firme e estável em qualquer clima? }\end{array}$ & $\begin{array}{l}\text { Sim, possui um piso regular, firme e } \\
\text { estável em qualquer condição climática. }\end{array}$ \\
\hline 9.2 .3 .1 & $\begin{array}{l}\text { O balcão de informação está localizado próximo à entrada e } \\
\text { pode ser facilmente identificado? }\end{array}$ & Conforme a norma. \\
\hline 9.2.3.4 & $\begin{array}{l}\text { O balcão de informação possui extensão mínima de } 0,90 \mathrm{~m} \text { e } \\
\text { altura entre } 0,9 \mathrm{~m} \text { e } 1,05 \mathrm{~m} \text { do piso? }\end{array}$ & $\begin{array}{l}\text { Possui a extensão, contudo não se } \\
\text { adequa quando à altura. }\end{array}$ \\
\hline 9.2 .1 .5 & $\begin{array}{l}\text { Os balcões de informação permitem aproximação frontal por } \\
\text { cadeira de rodas com profundidade livre inferior de } 0,30 \mathrm{~m} \text {, } \\
\text { permitindo uma comunicação mais eficaz? }\end{array}$ & $\begin{array}{l}\text { O balcão de atendimento de prioridades } \\
\text { não permite aproximação frontal. }\end{array}$ \\
\hline 9.2 .1 .2 & $\begin{array}{l}\text { Há espaço suficiente para manobra de cadeirantes para } \\
\text { rotação } 180^{\circ} \text { sem deslocamento de diâmetro de } 1,2 \mathrm{~m} \text { na } \\
\text { parte externa do balcão de informação? }\end{array}$ & Espaço suficiente. \\
\hline 9.3.1.2 & $\begin{array}{l}\text { As mesas ou superfícies de trabalho acessíveis, dentro do } \\
\text { guichê de informação e de atendimento, garante que um } \\
\text { cadeirante tenha aproximação frontal, com } 0,73 \mathrm{~m} \text { de altura } \\
\text { livre e } 0,50 \mathrm{~m} \text { de profundidade e } 0,80 \mathrm{~m} \text { de largura livre? }\end{array}$ & $\begin{array}{l}\text { Conforme a norma se tratando da altura } \\
\text { e da profundidade e a largura é } \\
\text { suficiente pois há, no máximo, apenas } \\
\text { dois atendentes no balcão. }\end{array}$ \\
\hline $\begin{array}{l}6.1 .1 .1 \mathrm{e} \\
9.2 .1 .1\end{array}$ & $\begin{array}{l}\text { Há pelo menos uma rota acessível para o atendimento, } \\
\text { trajeto contínuo, desobstruído e sinalizado que conecta a } \\
\text { entrada com o balcão de atendimento? }\end{array}$ & $\begin{array}{l}\text { O trajeto é desobstruído de materiais e } \\
\text { equipamentos, mas pode vir a ficar } \\
\text { obstruído com filas. }\end{array}$ \\
\hline 9.2 .1 .1 & O balcão de atendimento acessível e identificado? & $\begin{array}{l}\text { Há um balcão de prioridades, mas o } \\
\text { mesmo não é acessível. }\end{array}$ \\
\hline 9.2.1.2 & $\begin{array}{l}\text { Há espaço suficiente para manobra de cadeirantes para } \\
\text { rotação } 180^{\circ} \text { sem deslocamento de diâmetro de } 1,2 \mathrm{~m} \text { na } \\
\text { parte interna do balcão de atendimento? }\end{array}$ & Conforme a norma. \\
\hline 9.2 .1 .3 & $\begin{array}{l}\text { O projeto de iluminação permite que o paciente visualize a } \\
\text { face do atendente de uniformemente iluminada? }\end{array}$ & Conforme a norma. \\
\hline 9.2.1.4 & $\begin{array}{l}\text { O balcão acessível, disponibilizado para atendimento } \\
\text { preferencial, possui superfície com largura mínima de 0,90m } \\
\text { e altura entre } 0,75 \mathrm{~m} \text { a } 0,85 \mathrm{~m} \text { do piso? }\end{array}$ & $\begin{array}{l}\text { Há um balcão de prioridades, mas o } \\
\text { mesmo não é acessível. }\end{array}$ \\
\hline 9.2.1.5 & $\begin{array}{l}\text { Os balcões de atendimento permitem aproximação frontal } \\
\text { por cadeira de rodas com profundidade livre de } 0,30 \mathrm{~m} \text { ? }\end{array}$ & $\begin{array}{l}\text { O balcão de informação não permite } \\
\text { aproximação frontal. }\end{array}$ \\
\hline 5.3.5.1 & $\begin{array}{l}\text { Há indicação de atendimento preferencial, sinalizando os } \\
\text { beneficiários? }\end{array}$ & $\begin{array}{l}\text { Há sinalização de atendimento } \\
\text { preferencial sem indicação de } \\
\text { beneficiários }\end{array}$ \\
\hline $\begin{array}{l}8.9 .3 e \\
10.10 .3\end{array}$ & $\begin{array}{l}\text { Existe pelo menos um espaço reservado aos cadeirantes } \\
\text { junto ao mobiliário de espera com dimensões mínimas de } \\
0,80 \mathrm{~m} \text { por } 1,20 \mathrm{~m} \text { ? }\end{array}$ & $\begin{array}{l}\text { Não há espaço reservado para } \\
\text { cadeirantes. }\end{array}$ \\
\hline 10.3.1 & $\begin{array}{l}\text { Os espaços e assentos reservados para pessoas com } \\
\text { deficiências e/ou mobilidade reduzida está localizado em } \\
\text { uma rota acessível vinculada com uma rota de fuga? }\end{array}$ & \begin{tabular}{|l|} 
Não há espaços nem assentos \\
reservados para pessoas com \\
deficiência e/ou mobilidade reduzida.
\end{tabular} \\
\hline 10.3.1d & $\begin{array}{l}\text { Os espaços e assentos reservados para pessoas com } \\
\text { deficiências e/ou mobilidade reduzida está localizado em } \\
\text { local de piso plano e horizontal? }\end{array}$ & \begin{tabular}{|l|} 
Não há espaços nem assentos \\
reservados para pessoas com \\
deficiência e/ou mobilidade reduzida.
\end{tabular} \\
\hline 10.10 .2 & Há pelo menos um sanitário acessível no pavimento? & $\begin{array}{l}\text { Sim, há um sanitário acessível para uso } \\
\text { de ambos os sexos. }\end{array}$ \\
\hline 5.6.4.1 & $\begin{array}{l}\text { Há sinalização de emergência, com cor que contraste com a } \\
\text { parede, próximo à bacia e do boxe do chuveiro (se houver), } \\
\text { a uma altura de } 0,40 \mathrm{~m} \text {, para acionamento de uma pessoa } \\
\text { sentada ou em caso de queda? }\end{array}$ & $\begin{array}{l}\text { Não há sinalização de emergência no } \\
\text { sanitário acessível. }\end{array}$ \\
\hline 5.5.1.2 & $\begin{array}{l}\text { Há saída de emergência ou rota de fuga que seja sinalizada } \\
\text { e contenha informações visuais, sonoras e táteis? }\end{array}$ & $\begin{array}{l}\text { Não há indicação de saída de } \\
\text { emergência. }\end{array}$ \\
\hline
\end{tabular}

Fonte: Elaborado pela autora. 


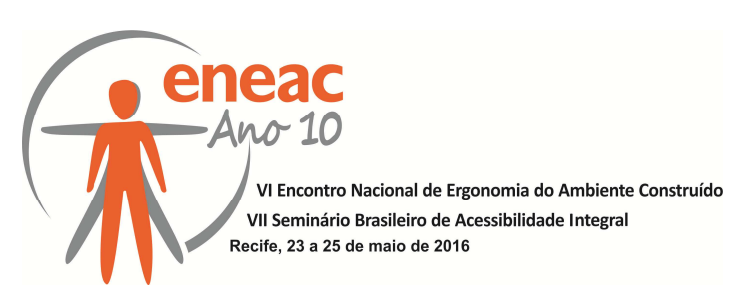

\subsubsection{Intervenções Ergonômicas}

Realizou-se um estudo dos itens não conformes sinalizados pelo questionário, em ordem aleatória, o que não implicam nos seus graus de importância, e concomitante a estas análises, será proposto/recomendado as intervenções necessárias para melhorias quando à acessibilidade do SMC. Ressalta-se que as imagens que simulam algumas destas intervenções são meramente ilustrativas, auxiliando o leitor no entendimento das adaptações sugeridas, não sendo elas o foco do presente trabalho. Inicialmente, analisou-se a parte externa.

A primeira proposta de melhoria está relacionada com a rota acessível. Devido à obra no local, não foi identificado as rampas de acesso necessárias, da rua para a calçada. Além disso, é preciso colocar piso tátil direcional e de alerta em toda a calçada e garantir pelo menos $1,20 \mathrm{~m}$ de faixa livre de circulação da rua até a porta de entrada, na rampa, na escada e na parte externa em frente a porta principal.

Os pisos táteis direcionais serão utilizados para auxiliar um portador de deficiência visual, independente da sua gravidade, a se deslocar por caminhos desobstruídos até o local desejado, em contrapartida, o piso tátil de alerta servirá para sinalizar o início e o final de rampas, escadas, portas, barreiras, mudança de direção, algum mobiliário obstruindo àquela direção ou alerta de perigo.

Nas escadas, necessário colocar corrimão em ambos os lados da mesma e manter o corrimão intermediário, devido ao fato da escada ter mais de $2,40 \mathrm{~m}$, exigido no item $\mathrm{n}=6.9 .4$ (ABNT, 2015). Os corrimãos deverão ter suas alturas de estar de acordo com a norma, sendo elas 0,92m e 0,70m do piso, como indicado no item no 6.9.2.1 (ABNT, 2015). Nas rampas e nas escadas, que também fazem parte de uma rota acessível, necessitam de ajustes nos corrimãos que não possuem um prolongamento de $0,30 \mathrm{~m}$ nas extremidades, conforme o item no6.9.2.2 (ABNT, 2015). Utilitário este que auxilia no apoio de portadores de deficiências e/ou mobilidade reduzida.

Por fim, necessita colocar o símbolo de acessibilidade em local visível na entrada do edifício como previsto no item no 5.3.2.2 (ABNT, 2015). A figura 1 retrata, por meio de simulação, as melhorias acima citadas.

Figura 1 - Simulação do subsistema estudado - SMC

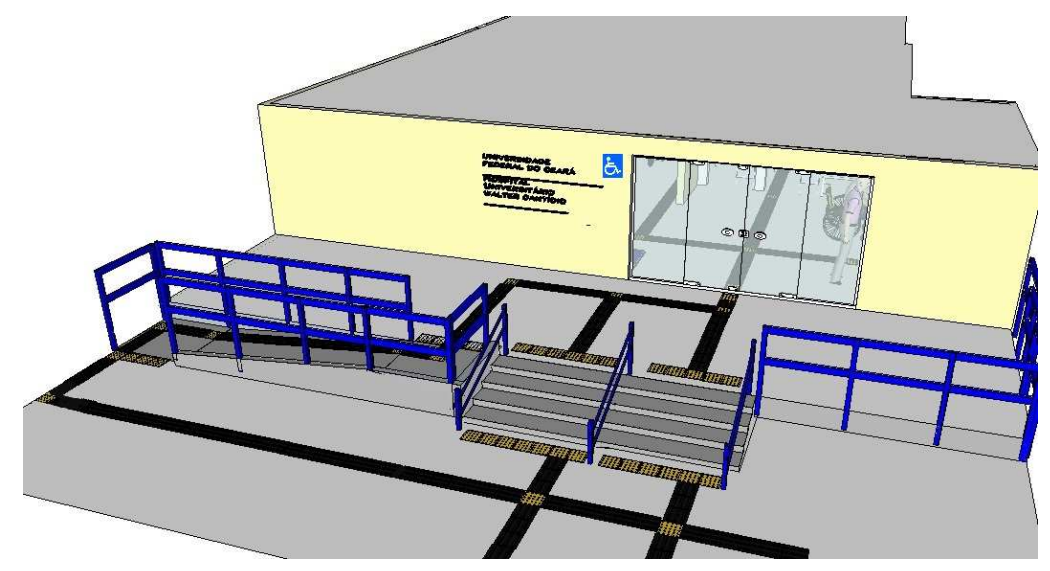

Fonte: Elaborado pela autora 


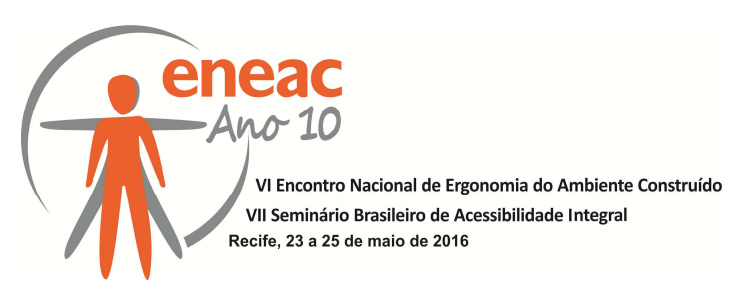

Posteriormente, tratou-se de analisar o balcão de informações. O mesmo se encontrava com altura de $1,10 \mathrm{~m}$, atualmente considerado não conforme de acordo com o item no 9.2.3.4 (ABNT, 2015), necessitado ser adaptado para as alturas corretas, 0,90 m a 1,05 m.

Propõe-se também uma adequação para que em uma parte do balcão, com extensão mínima de 0,90m e altura livre de 0,73 m, permita a aproximação frontal de 0,30 m por um indivíduo com cadeira de rodas, permitindo uma comunicação mais eficaz. Tal melhoria está prevista no item no 9.2.1.5 (ABNT, 2015).

Além disso, sugere-se como melhoria a adição de um sistema para distribuição de senhas numéricas, a fim de evitar filas desnecessárias.

Os colaboradores do guichê de informação ficaram responsáveis de verificar todos os documentos do paciente e o encaminharia para o atendimento adequado, através de senhas, somente no caso de o paciente estar com todos os documentos corretos.

Aplicado esse sistema de triagem, 0 paciente se encontrará livre para aguardar 0 atendimento confortavelmente sentado, com a certeza de que realizará o agendamento da consulta como esperado.

Os painéis de senhas, destinados à visualização de números de forma sequencial, torna possível controlar o fluxo dos pacientes aos guichês de atendimento, estimar a eficiência de cada funcionário e verificar a demanda real, bem como proporciona uma transparência para os pacientes quanto ao tempo de espera. Tal dispositivo pode custar de $R \$ 500,00$ a $R \$$ 2500,00 , variando de acordo com a tecnologia empregada. A figura 2 possibilita visualizar as adaptações e melhorias sugeridas no guichê de informação.

Figura 2 - Simulação guichê de Informação

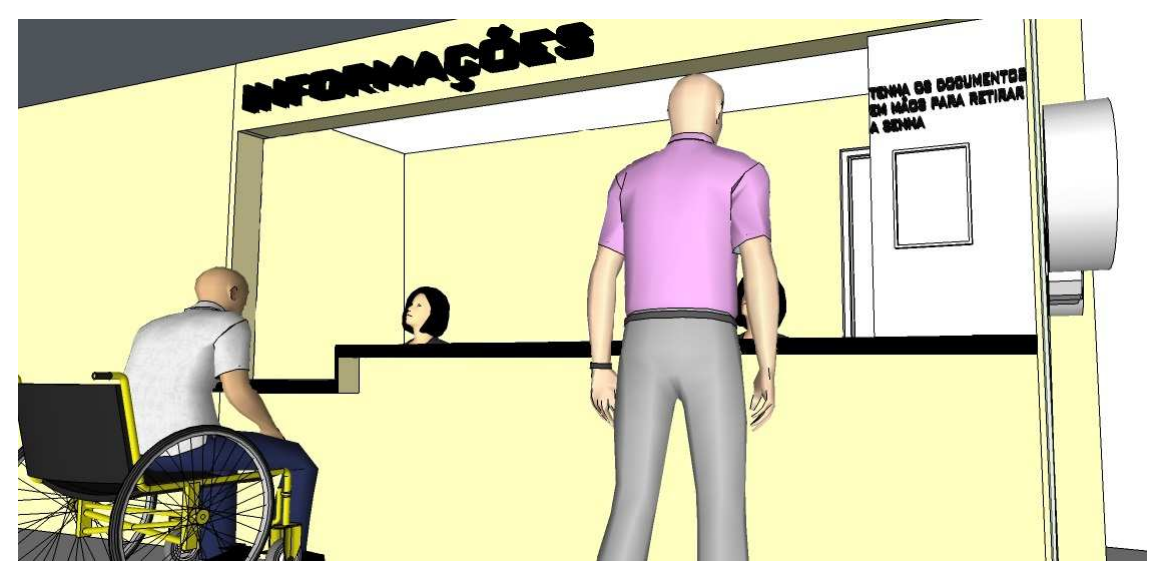

Fonte: Elaborado pela autora

Da porta de entrada para o balcão de informação e de atendimento bem como às áreas internas do Ambulatório, é necessário pelo menos uma rota acessível, com faixa livre de 1,20m no mínimo e sinalização tátil direcional e de alerta, determinados nos itens $n^{\circ}$ 6.1.1.1, no 6.1.1.2 e no 5.4.6.4, respectivamente.

Outra melhoria e intervenção a ser proposta, trata-se do guichê de atendimento preferencial. Visando possibilitar uma rota acessível, da entrada ao guichê, de acordo com as normas descritas acimas, seria necessário transpor a fila de prioridades localizada ao lado da janela para o guichê mais próximo à entrada principal, possibilitando que haja espaço suficiente para cadeirantes se movimentarem e manobrarem suas cadeiras, como exigido no item no 9.2.1.2 (ABNT, 2015), bem como um corredor amplo com corrimão para que pessoas com 


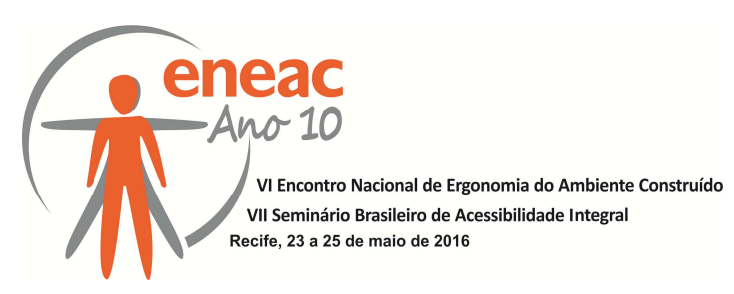

necessidades especiais e/ou mobilidade reduzida consigam apoio necessário que gere conforto e segurança.

Após essa mudança do local do guichê de prioridade, também se tornará necessária a adequação do mesmo de acordo com a norma, visando a acessibilidade e facilitando a comunicação com o atendente.

Tais adaptações englobam a adequação na altura e largura do balcão acessível, como indicado no item no 9.2.1.4 (ABNT, 2015), assumindo as medidas de altura livre entre $0,75 \mathrm{~m}$ a $0,85 \mathrm{~m}$ do piso e $0,90 \mathrm{~m}$ de largura mínima. O guichê de prioridade precisa ser facilmente identificado e sinalizado com os beneficiários desse atendimento, conforme os itens ํㅡ 9.2.1.1 e no 5.3.5.1 (ABNT, 2015), respectivamente.

Outros pontos de melhorias identificados foram na ausência de assentos preferenciais e espaço reservado para cadeirantes junto ao mobiliário de espera. Assim como exemplifica a figura 3, tais pontos são possíveis de serem adaptados.

Figura 3 - Simulação da parte externa dos guichês de atendimento

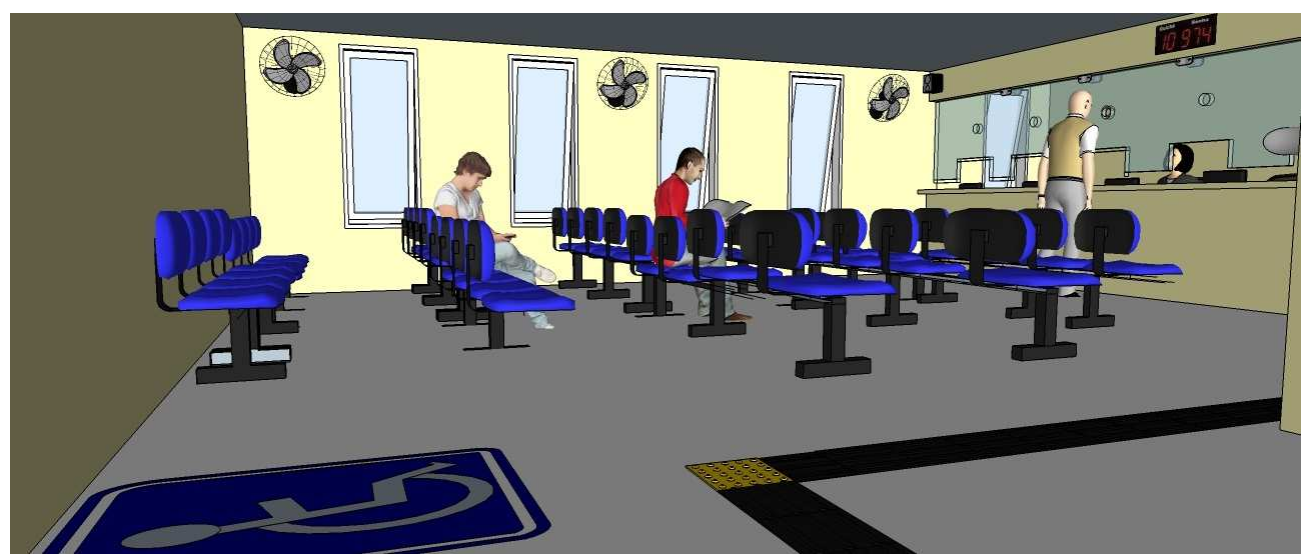

Fonte: Elaborado pela autora

De acordo com os itens ํo 8.9.3 e no10.10.3 (ABNT, 2015) é necessário reservar pelo menos um espaço com dimensões mínimas de $0,80 \mathrm{~m}$ por $1,20 \mathrm{~m}$ para cadeirantes. As quantidades de espaços necessários por ambiente podem e dever ser quantificadas, variando de acordo com o número de assentos totais. Tais valores podem ser encontrados em outras normas da ABNT, não sendo estas o foco do presente trabalho.

Assim como os cadeirantes, pessoas obesas necessitam de assentos especiais, conforme

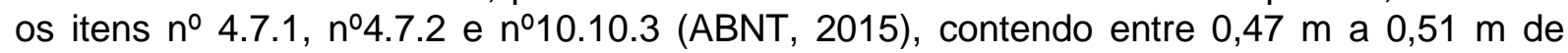
profundidade, com largura mínima de $0,75 \mathrm{~m}$, com altura entre $0,41 \mathrm{~m}$ e $0,45 \mathrm{~m}$ e podendo suportar uma carga de $250 \mathrm{~kg}$.

Tendo dito isso, como melhoria propõe-se reservar espaços para cadeirantes e assentos para pessoas obesas e portadores de deficiência e/ou mobilidade reduzida em piso plano, próximo à saída de emergência, no caso do SMC é a saída principal. Sugere-se também localiza-los em local que permita as mesmas condições de conforto, boa visibilidade e acústica dos outros assentos, assim como é especificado no item nำ10.3.1 (ABNT, 2015). Algumas das melhorias propostas para os guichês de atendimento podem ser visualizadas na figura 4. 


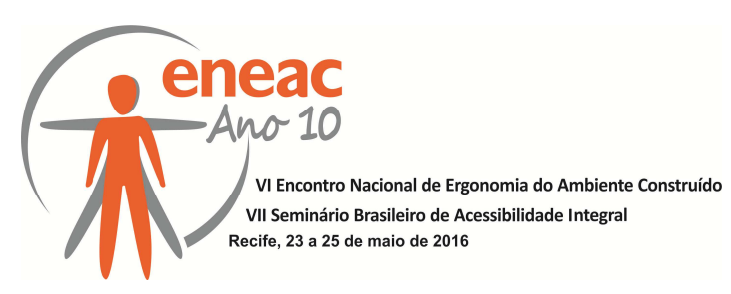

Figura 4 - Simulação dos guichês de atendimento

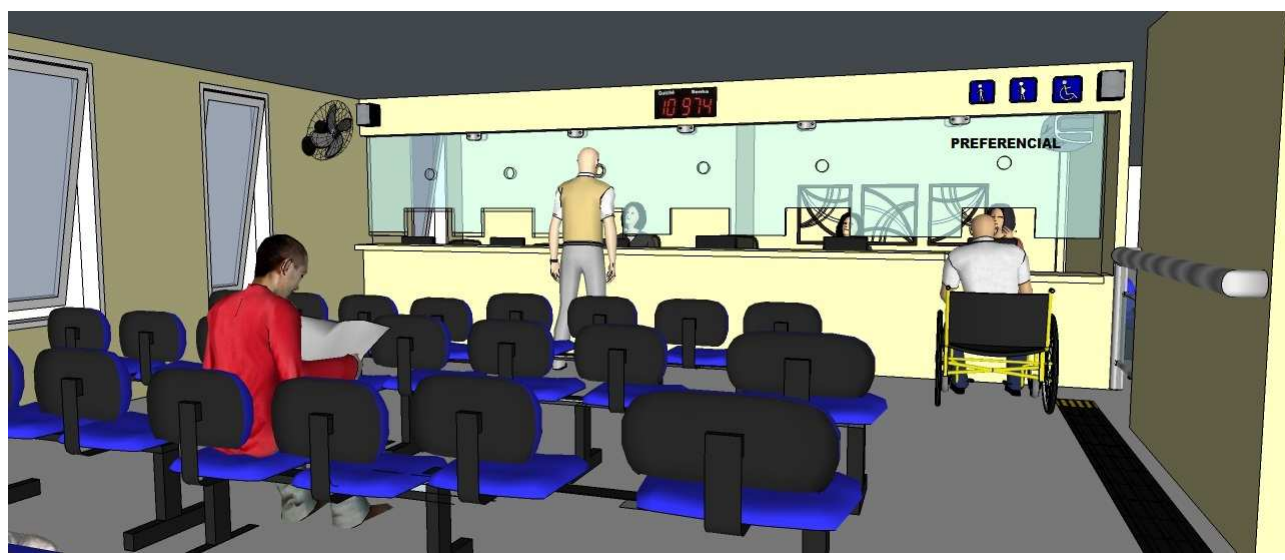

Fonte: Elaborado pela autora

A figura 5 permite visualizar a rota acessível entre o corredor e os sanitários acessível, localizados na parte interna do Ambulatório, com sinalização tátil direcional e de alerta.

Figura 5 - Simulação do acesso às áreas internas

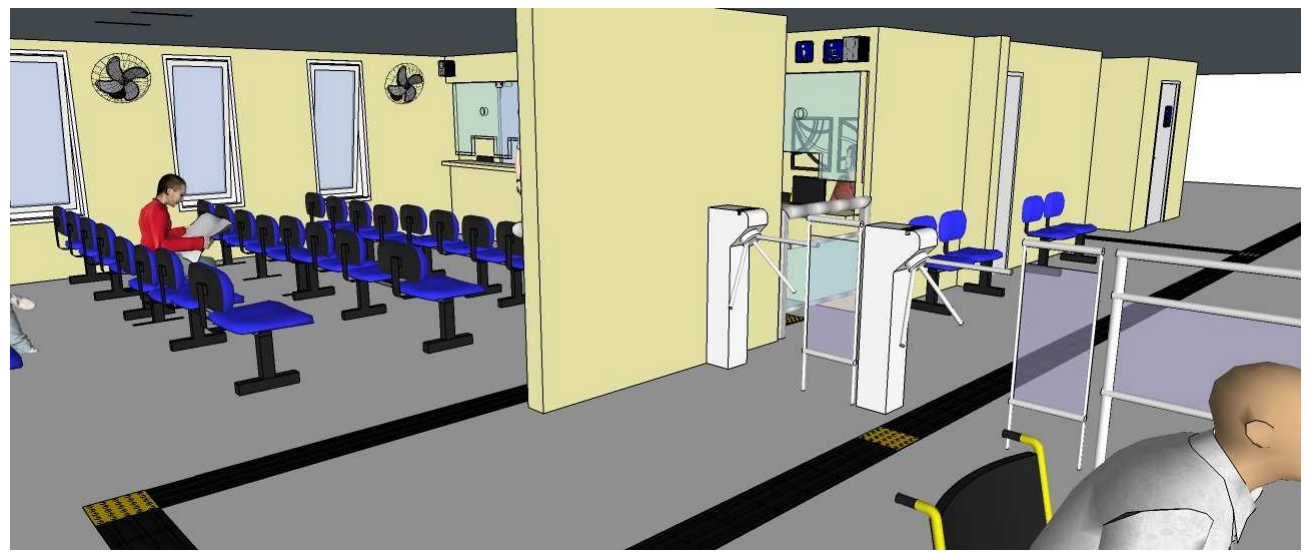

Fonte: Elaborado pela autora

Seguindo com as não conformidades sinalizadas no questionário, é de fundamental importância propor como melhoria as sinalizações de emergência. Como exigido no item no5.6.4.1 (ABNT, 2015), é necessário haver sinalização de emergência no sanitário acessível, com cor que contraste com a parede, próximo à bacia e do boxe do chuveiro, a uma altura de 0,40 m, para acionamento de uma pessoa sentada ou em caso de queda. É necessária, ainda, a sinalização de emergência que direcione, por meio de sinais, o usuário para a saída de emergência ou rota de fuga. Como no SMC, a saída de emergência coincide com a entrada principal, a mesma deve ser sinalizada por meio de sinais visuais, sonoro e táteis, como especificado nos itens n-5.5.1.1 e n-5.5.1.2. Por fim, e não menos importante, propõe como pontos de melhorias dentro dos guichês de atendimento e de informação, para que o mesmo seja acessível no caso de haver atendentes portadores de deficiência e/ou mobilidade reduzida, que as portas internas se adequem de acordo com o item no6.11.2.4, com vão livre de no mínimo 0,80 m e 2,10 m de altura. 


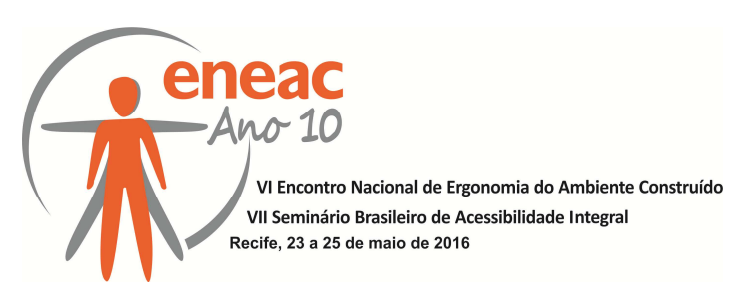

\section{CONCLUSÕES}

Propostas de adaptações de acessibilidade no Hospital Universitário Walter Cantídio foram fundamentadas a partir de um estudo de caso do Setor de Marcação de Consultas, visando torná-lo acessível para utilização plena e autônoma por todos seus usuários. Pelo estudo de caso, percebeu-se que o referido hospital público já apresenta uma relativa preocupação sobre as condições de acessibilidade com relação às pessoas portadoras de deficiências e/ou mobilidade reduzida, tanto quanto com a saúde, conforto e bem-estar de seus funcionários e pacientes. Contudo, algumas modificações ainda se fazem necessárias.

Pela análise de adequação à NBR 9050/2015, concluiu-se que são necessárias reformas de adaptação ao espaço físico, de maneira a contemplar a acessibilidade em todo o ambiente do subsistema hospitalar em questão. Exemplos de adaptação compreendem a criação de rotas acessíveis, a sinalização de emergência e a reserva de espaços para cadeirantes e assentos para pessoas obesas e portadores de deficiência e/ou mobilidade reduzida em piso plano. Tais medidas podem contribuir para um melhor atendimento às reais necessidades dos usuários e funcionários, adequando tal setor poderá à norma NBR 9050, de modo a potencializar a acessibilidade no ambiente estudado.

\section{REFERÊNCIAS BIBLIOGRÁFICAS}

ARAUJO, T. G. Propostas de adaptações de acessibilidade baseadas na NBR 9050: Estudo de caso no Hospital Universitário Walter Cantídio. 2016. 77f. Monografia de Graduação em Engenharia de Produção Mecânica - Universidade Federal do Ceará. Fortaleza - CE.

ASSOCIAÇÃO BRASILEIRA DE NORMAS TÉCNICAS. NBR 9050: Acessibilidade a edificações, mobiliário, espaços e equipamentos urbanos. Rio de Janeiro, 2015.

BRASIL. Lei no 13.146 de 06 de julho de 2015. Institui a Lei Brasileira de Inclusão da Pessoa com Deficiência (Estatuto da Pessoa com Deficiência). Diário Oficial da União (DOU), Brasília, DF, 7 jul. 2015. Disponível em: <http://www.planalto.gov.br/ccivil_03/_Ato2015-2018/2015/Lei/L13146.htm>. Acesso em: 05 jan. 2016.

DISCHINGER, M.; ELY, V. H. M. B.; PIARDI, S. M. D. G. Promovendo acessibilidade espacial nos edifícios públicos: Programa de acessibilidade às pessoas com deficiência ou mobilidade reduzida nas edificações de uso público. Florianópolis: MPSC, 2012. 161 p. Disponível em: <http://www.mpam.mp.br/attachments/article/5533/manual_acessibilidade_compactado.pdf>. Acesso em: 05 jan. 2016.

IIDA, Itiro. Ergonomia: projeto e produção. 2. ed. São Paulo: Blucher, 2005.

INSTITUTO BRASILEIRO DE GEOGRAFIA E ESTATÍSTICA (IBGE). Censo Demográfico 2010: resultados do Universo. Rio de Janeiro, 2010.

ZURBA N.K, et al., Metodologia experimental de ensino-aprendizagem para o design de produtos biomédicos: BIO-MEAD. In: P\&D DESIGN: Congresso Brasileiro de Pesquisa e Desenvolvimento em Design, 11., 2014, Gramado. Anais eletrônico. Gramado: UFRGS. 2014. Disponível em: <http:www.ufrgs.br/2014/trabalhos/1069_arq2.pdf>. Acesso em: 15 abr. 2015

\section{AGRADECIMENTOS}

Agradecemos aos funcionários do HUWC pelo apoio e realização da Visita Técnica às instalações do hospital, em aula-prática realizada no âmbito disciplina Ergonomia I ministrada pela Prof ${ }^{a}$. Dra ${ }^{a}$ Nadia Khaled Zurba, no semestre de 2015.1, e à Prof. Dra. Zilsa Pinto Santiago, pelos auxílios de mobilidade da Secretaria de Acessibilidade da UFC. 